\title{
Case reports of benign intrascrotal tumors: Two epidermoid cysts and one scrotal calcinosis
}

\author{
Tuncay Toprak ${ }^{1}$, Cagri Akin Sekerci ${ }^{2}$ \\ ${ }^{1}$ Department of Urology, Fatih Sultan Mehmet Training and Research Hospital, Istanbul, Turkey; \\ ${ }^{2}$ Marmara University Pendik Training and Research Hospital, Pediatric Urology, Istanbul, Turkey
}

\begin{abstract}
Summary Background: The aim this study was to explain the underlying etiology of unknown

scrotal masses.

Case presentation: This study included 3 patients with a intrascrotal mass. One patient was over 50 years. The remaining patients were between the ages of 30-50. Patients had no serious complaints (two complained about having 3 testicles and one complained of swelling in the scrotum for the last 6 months). All patients underwent scrotal exploration under general anesthesia and the specimen was sent for pathological examination. All masses were mobile and encapsulated. The masses were not associated with the testicle. Two cases had classical histologic features of epidermoid cyst and one had scrotal calcinosis in the pathological report. Physical examination, operation, magnetic resonance and histological images of scrotal masses were shown in the figures.

Conclusions: This study is important in terms of showing the underlying etiology of the rare scrotal masses.
\end{abstract}

KEY WORDS: Intrascrotal; Epidermoid cyst; Calcinosis cutis.

Submitted 29 November 2019; Accepted 30 December 2019

\section{INTRODUCTION}

Epidermoid cysts (ECs), also known as sebaceous cysts, are most common encapsulated cysts and usually these cysts have no potential for malignancy (1). The cyst filled with keratin and inflammatory reaction develops due to the outflow of keratin, and many practitioners mistakenly diagnose abscesses and prescribe antibiotics. Although it is known as benign, it has been reported that approximately $1 \%$ of these cysts may develop into squamous or basal cell carcinoma. ECs may be found in autosomal dominant Gardner and Gorlin syndrome but most cases are seen as sporadic (2). Scrotal calcinosis (SC), another benign lesion in the scrotum, is a rare disease characterized by multiple papules or calcification nodules in scrotal skin (3). In this study we discussed two cases of epidermoid cysts and one scrotal calcinosis. This study showed the etiology of the rare intrascrotal masses and contributing to the literature about the diagnosis, follow-up and treatment of these masses.

\section{Case reports}

Written informed consent was obtained from patients for the publication of this case reports. This study included 3 patients who underwent surgery due to the intrascro- tal mass between 2018-2019. The laboratory data and tumor markers of all patients were within normal limits in this study. Two was complaining about having 3 testicles and one was complaining of swelling in the scrotum for the last 6 months. The patients were 60, 40, and 35 years old, respectively. All patients had no history of comorbidity, drug use or history of operation. All masses on the physical examination were mobile and well limited. Two on the right side and one on the left side. All patients underwent scrotal exploration under general anesthesia. The masses were not associated with the testicle. During the operation, the adherent skin was dissected and the skin was separated from the mass in two patients. The specimen was sent for pathological examination. Two of the patients had pathological results of EC and one had calcinosis cutis. Pathological images of patients were presented in Figures 3, 4 and 5. Figure 1 shows preoperative, intraoperative and postoperative images of a intrascrotal mass which is later diagnosed histologically with EC. Figure 2 shows preoperative T1, $\mathrm{T} 2$ and diffusion-weighted magnetic resonance (MR) images of EC separated from the testis. Following resection of the intrascrotal mass two patients had no recur-
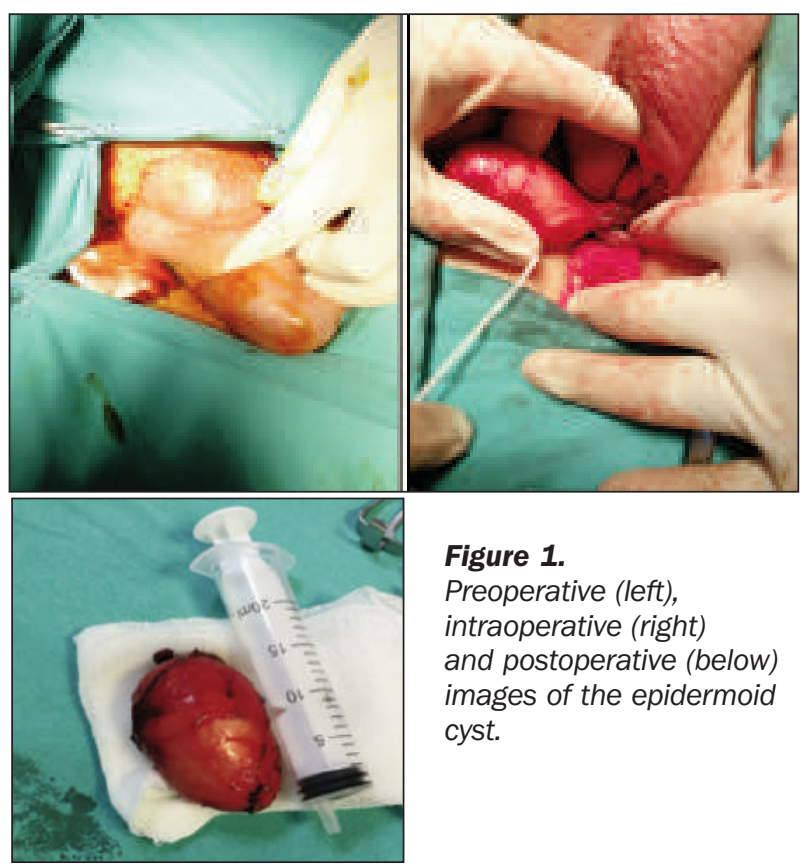

Figure 1.

Preoperative (left), intraoperative (right) and postoperative (below) images of the epidermoid cyst.

No conflict of interest declared. 


\section{Figure 2.}

T1 (left), T2 (right) and diffusion-weighted MR images of the epidermoid cyst.

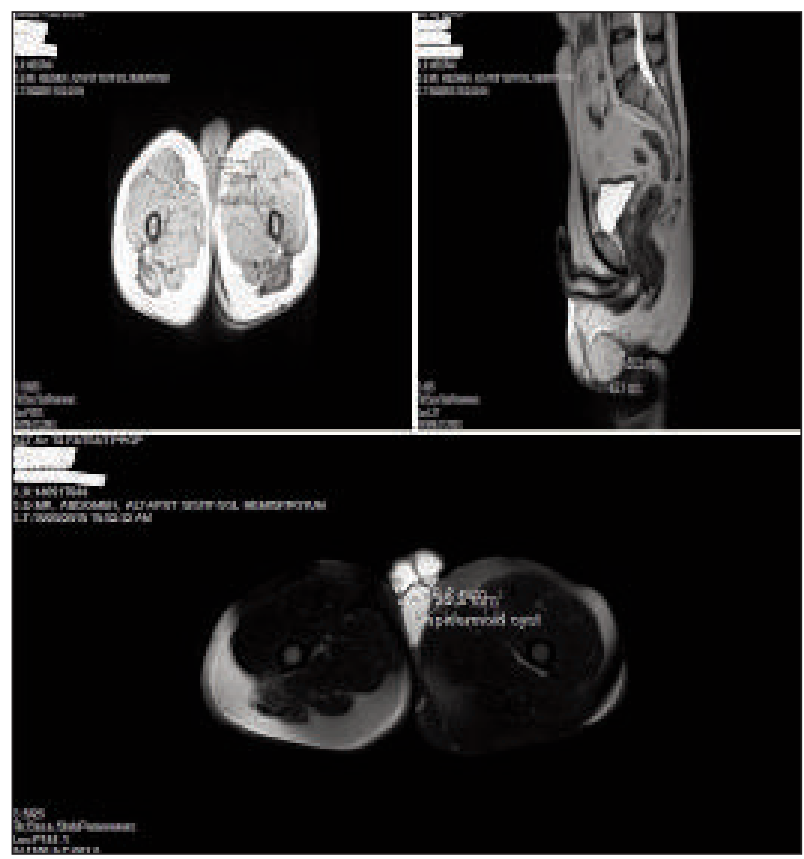

\section{Figure 3.}

Epidermoid cyst; surrounded with stratified squamous epithelium. Lamellar keratinous material is observed in the lumen. $H$ \& Ex40 (left figure).

Granular layer in stratified squamous epithelium.

Lamellated keratinous material is observed on the surface of the epithelium. $\mathrm{H} \&$ Ex400 (right figure).

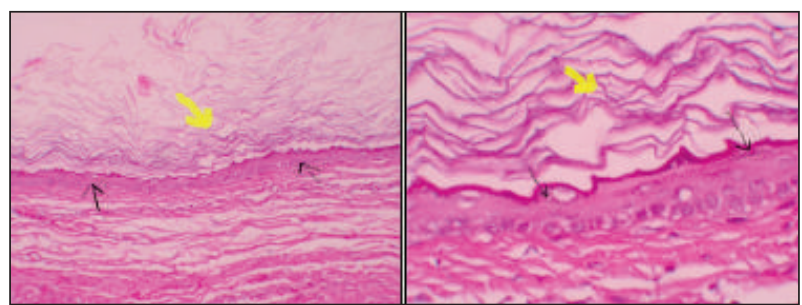

rence up to 8 months and one patient had no recurrence up to 5 months and no complication was observed.

\section{Discussion}

ECs are epithelial cysts and are generally known as nonmalignant (1). In general, these cysts are caused by the occlusion of the follicular orifice. In addition, ECs may occur after traumatic or penetrating injuries leading to epithelial implantation (4). These cysts are composed of a sac surrounded by a stratified squamous epithelium filled with debris, keratin and cholesterol crystals (5).

A granular layer is present that is filled with keratohyalin granules (Figure 3). The EC may be associated with the testicle in the scrotum or may be completely separate.

In T2-weighted magnetic resonance imaging (MRI), these cysts are observed as high-density, well-limited solid masses surrounded by a low-signal capsule (6). The patients in the study showed the same MRI findings.
Figure 4.

Epidermoid cyst; surrounded with stratified squamous epithelium. $H$ \& E x40 (left figure).

Ruptured area, granulomatous reaction is observed under the multilayer squamous epithelium (right figure).

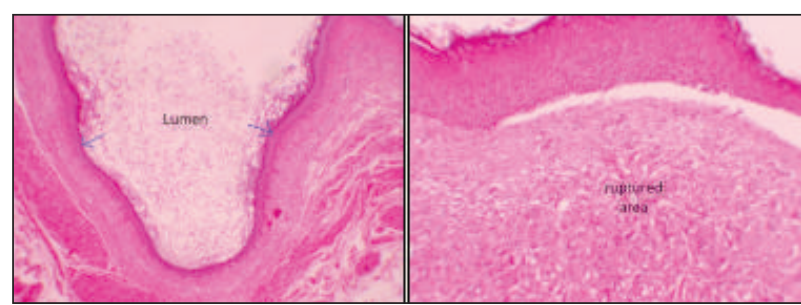

Figure 5.

Calcinosis cutis; the epidermis on the surface is regular. Granular calcified material is surrounded by fibrosis in the dermis $H$ \& Ex40 (left figure).

Granular calcified material is observed in the dermis and fibroblastic proliferation is observed around it $H \&$ Ex100 (right figure).

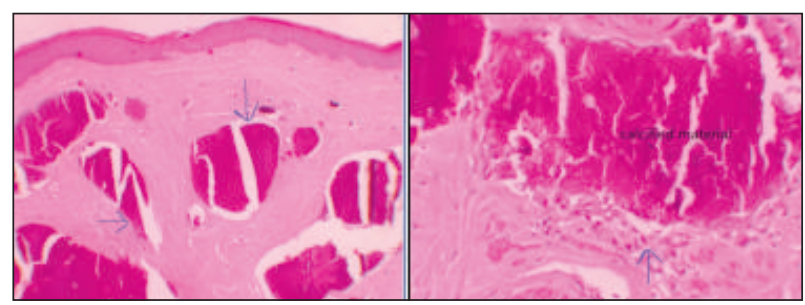

Due to the suspicion of testicular cancer, the preoperative diagnosis of an EC is very difficult. Complete surgical excision with the cyst wall is considered the the most effective treatment for an EC. Generally, cysts are asymptomatic but when rupture as in one patient in the study, an inflammatory reaction occurs because of the displacement of the keratin into the dermis and surrounding tissue (Figure 4). The evalution is largely based on history and physical examination. Physical examination usually shows a non-fluctuant, compressible mass between 0.5 $\mathrm{cm}$ and several centimeters. Although laboratory examination is not necessary, it can be recommended to take tumor markers when there is a suspicion of testicular cancer. Scrotal MRI was performed in the first few patients. However, it was concluded that it did not benefit much. Calcinosis cutis, another intrascrotal mass in the study, was characterized by multiple papules or calcification nodules on the scrotal skin, but in our patient this was larger than normal SC nodules and was a single lesion in the scrotum. The pathology showed classical histologic features of SC with a granular calcified material in the dermis and fibroblastic proliferation around it (Figure 5). It could be traced to originate from calcification of epidermal cyst or hair follicular and then the epithelial elements disappeared, leaving behind residual areas of calcification.

\section{Conclusions}

This study is valuable in terms of showing the etiology of the rare intrascrotal masses and contributing to the literature about the diagnosis, follow-up and treatment of ECs. 
Acknowledgements: We would like to thank to Fatih Sultan Mehmet Hospital Pathology Department for providing histological images.

\section{References}

1. Prasad KK, R. Manjunath R Multiple epidermal cysts of scrotum. Indian J Med Res. 2014; 140:318.

2. Zito PM, Scharf R. Cyst, Epidermoid (Sebaceous Cyst), in StatPearls (Internet). 2019, StatPearls Publishing.
3. Tareen A, Ibrahim RM. Idiopathic scrotal calcinosis-A case report. Int J Surg Case Rep. 2018; 44:51-53.

4. Karaci S, Kulaksiz D, Sekerci CA. A rare cause of clitoromegaly: epidermoid cyst. Arch Ital Urol Androl 2019: 91:137-8.

5. Shah KH, Maxted WC, Chun B. Epidermoid cysts of the testis: a report of three cases and an analysis of 141 cases from the world literature. Cancer. 1981; 47:577-582.

6. Cho JH, Chang JC, Park BH, et al.. Sonographic and MR imaging findings of testicular epidermoid cysts. AJR Am J Roentgenol. 2002; 178:743-8.

\section{Correspondence}

Tuncay Toprak, MD (Corresonding Author)

drtuncay55@hotmail.com

Department of Urology, Fatih Sultan Mehmet Training and Research Hospital Anabilim Dalı Atasehir, Istanbul (Turkey)

Cagri Akin Sekerci, MD

cagri_sekerci@hotmail.com

Marmara University Pendik Training and Research Hospital, Pediatric Urology, Istanbul (Turkey) 